\title{
Infusing Design In The Jua Kali (Informal Sector) Production
} Processes

\author{
Samuel M. Maina (PhD), Robert W. Rukwaro (PhD), Walter H. Onyango \\ $(\mathrm{PhD})$, \\ University of Nairobi, School of the Arts and Design \\ University of Nairobi, School of the Built Environment
}

\begin{abstract}
Since its inception in the mid-1970s and early 1980s, the Jua Kali (informal sector) has been popular to the consumers because of its affordable articles and proximity to residential areas. This paper looks at the amalgamation of design and production to offer solutions to problems artisans face in trying to meet consumer satisfaction. Materials, comfort, cost of articles, labour issues and skills, proprietors and apprentices terms of employment and how they can be interpreted to synthesis a brief to the satisfaction of the client were considered. It applied a case study model while applying a survey method for data collection. The sample size was 300 workshops in Gikomba market, Nairobi City of which 188 workshops were engaged in wood production while the rest of 112 workshops were engaged in metal production. The study found out that this informal sector grapples with the problem of quality, funding and the ability to purchase materials and adequate labour. The study established the sector has minimal or no specialisation in labour. However, it identifies one advantage that their products are affordable to most low income earners due to economies of scale in their production and proximity. It thus recommends that the informal sector considers acquiring requisite design skills, standardisation, quality control, ergonomics and aesthetics in production.
\end{abstract}

Key words: ergonomics, product design, Jua Kali, quality production,

\section{INTRODUCTION}

The ability for an economy to design useful products is tied to its productivity, thus economic growth and the population's standards of living. This paper investigates product design strategies and processes in Kenya in the country's informal sector. In Kenya, the Jua Kali is classified as the "informal sector". This is largely due to the terms of employment characteristics such as presence or absence of official recognition for taxation, trade union organization and security of employment (Aleke, 1988). The term 'Jua Kali' means "hot sun" which implies that the artisans operate in open air outdoor or makeshift workshops, because of lack of workshops, on the outskirts of major urban areas in Kenya (Onyango, 2002). Operatives are subjected to arrest, in some cases, because they lack operational licences. Since the mid 1970s Kenya has experienced problems with formal employment, the reason being that the dwindling economy is unable to absorb majority of school leavers (Abagoye, 1986). The other option is self-employment in the "informal sector". The Jua Kali apprentices are normally migrants from the countryside with little or no training. They mostly get employed on casual or temporally basis. Because of their lack artisanal training, they are not in a position to understand and integrate principles and basic skills in design. The affluent Kenyans have therefore increasingly shunned local furniture commonly made by Jua Kali Artisans. This furniture is displayed on roadsides. The affluent Kenyans opt instead for imported pieces stocked in malls and supermarket chains. Mall retailers source large volumes of standardised pieces, contrary to the piece-by-piece production that local manufacturers typically focus on. Jua Kali enterprises have limited access to formal retail because their products lack quality assurance, standardisation and volume (Donaldson, 2006). This means growing consumer demand is increasingly met by imports in the first place and formal manufacturers in the second place.Between 2009 and 2013, furniture imports grew at a rate of almost $24 \%$ compared to a $10 \%$ growth for the overall furniture market in Kenya economic survey. Today, imports constitute $13 \%$ of total domestic furniture sales, with seats and office furniture being particularly favoured. Data shows that the cost of producing the same items are as high as $40-50 \%$ higher in Kenya compared to the main import sources of China and Malaysia.Locally manufactured furniture is not cost-competitive vis-à-vis imported furniture. In fact, Kenyan products are only competitive in local and regional markets after import duties (25\%) and shipping costs are considered. The local industry is also facing limited skills and the use of outdated technology. The main purpose of this study is to establish quality of Jua Kali product and the role of artisans in realising these products. The significance of this study is to develop a design and production model fit for Jua Kali artisans to enable them improve the craftsmanship. 


\section{PROBLEM STATEMENT}

Growth of the Jua Kali has been hampered by LACK of authenticity in designs and hindered creativity levels due to duplication of products in the sector. The Jua Kali artisans do not conform to design practices; hence their products are not original. Also, their products lack cultural settings and are replicas of fellow artisans resulting in monotonous duplication. Additionally, the quality of the product is poor due to the lack of precise tools and suitable work environment (Figure 1). The products therefore sell cheap to compensate the compromised quality. These products lack aesthetics resulting in unattractive items due to lack of skills or training in design. The problem experienced in Jua Kali industry show inconsistency in precision and ends up in unbalanced items in terms of ergonomics and anthropometrics (Figure 2). This accounts for lack of standardisation unlike in the formal sector.

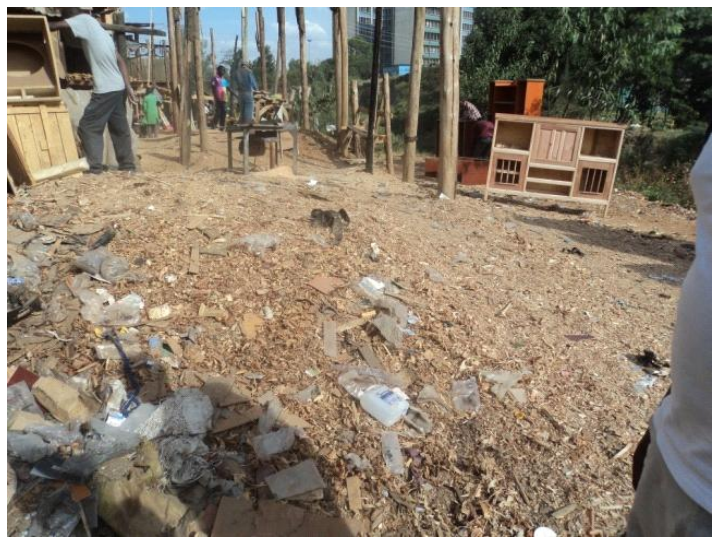

Figure 1: Unsuitable work environment Source: Field survey 2016

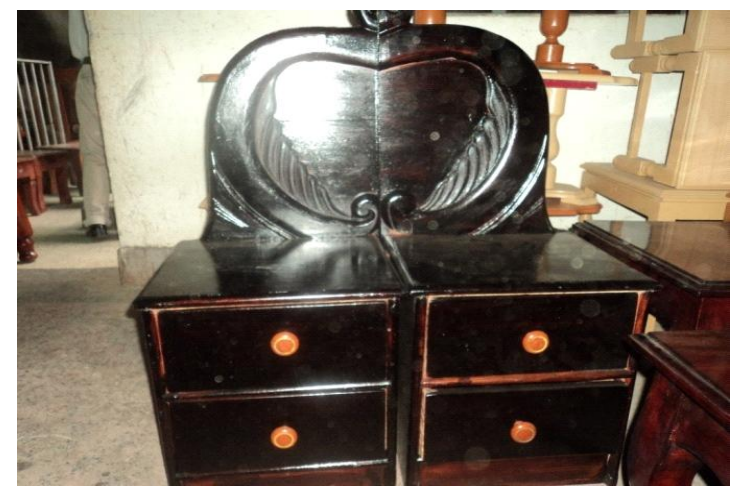

Figure 2: Inconsistent colour application, see the edges of drawers Source: Field survey 2016

\section{THEORY}

The word design has different meanings in different fields. It ranges from graphic design to typographic design, engineering design, architectural design, design for society, systems design and fashion design (Armante, 1988). In this aspect, design is the direct result of specialization in industry. Specialization in industry resulted into the development of industrial design, long before the emergence of 'industrial design' as a profession.The discoveries of science made it possible for the industrial revolution and the highly complex urban surroundings. During the industrial revolution, numerous developments in production process were made such as development of machine tools industries, introduction of precision instruments leading to standardization to name a few. Figure 3 presents standardised, simple, desirable and aesthetic neatly constructed and precisionaly made by Gerit Rietveld (Rietveld, c. 1923).Mass production was very new when applied on a vast scale. This slowly topped the developed traditions of centuries. As soon as such traditional crafts methods were broken up, industrial methods emerged, leading to a designer being of a necessity. The new system of production required someone to carry on the creative and formative aspect of the craftsman's work. In this way a designer was needed to guide the design and production processes. 


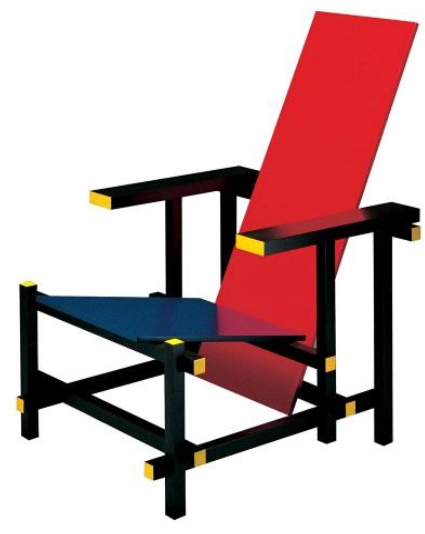

Figure 3: French 1918 Red and blue chair

Source: Rietveld c. 1923

From the 1960s up to 1970s, aesthetics and art were almost eradicated from the designers' vocabulary. Designers competed with engineers and desired recognition from men and industrialists. Standardization, measurability, concreteness and rationality were the keys to assessment of design effectiveness. The major contribution to the profession during this period in the long term perspective is to be found on two levels; that of multi-disciplinarity, where a quality designer still maintains a special characteristic not shared by other professionals, and that of analysing a design process systematically, thereby seeing design as a process rather than a product. As much as a designer is connected to the world of art, the designer is not a "fine artist". The artist basically expresses himself while the designer expresses the product (Adrian, 1992).The innovative designer does not recycle designs year in year out. Instead, there is need for creativity so as to come up with new designs each year. It is paramount to have a good data bank of sketches upon which to easily extract new range of designs when required. Design is also a process of communication between a designer and a consumer. The product is the object of communication and it expresses the message in a visual code (Gantz, 2014).

According to paradigms of cognitive psychology, thinking, acting and perceiving are guided by mental schemata and cognitive models. Thus, communication process must be guided by cognitive models. The following construction process model captures these relationships (Figure 4).

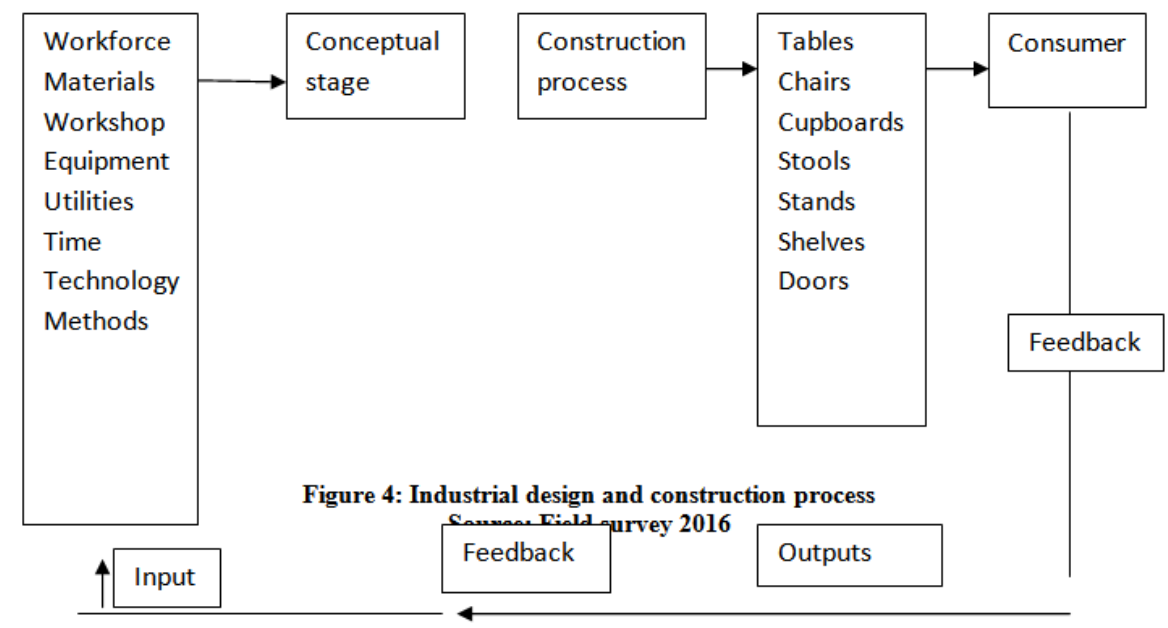

Figure 4: Industrial design and construction process Source: Field survey 2016

According to Norman (1988), communication in design is directed by conceptual models called "design model" and the "user model". When designers start their work, they first have a mental representation, a conceptual model. They subsequently develop the ideas into two or three dimensional object and code it in the "systems appearance (Figure 5). The process can be successful when designer's conceptual model fits that of the consumer context. It is therefore of interest for the designer to obtain information about the user's cognitive model qualities. 


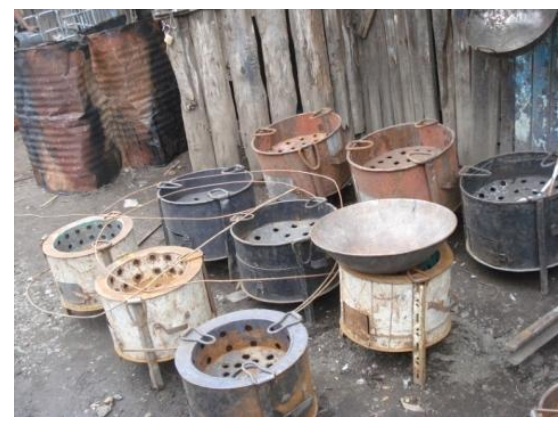

Figure 5: Cognitive shock? Poorly finished charcoal stovesSource: Field survey 2016

In this study, works by Walter Gropius, who was the director of Bauhaus design school in Dessau in 1926 and author of art and design were taken into consideration. During this time, there was creation of a practical frame for the activities of the School while aiming at making a new image of how man's architectural environment visually manifest. The educational philosophy of the Bauhaus sought a new synthesis of art and technology: that is "to give the products of the machine content of reality and significance." To achieve this, the Bauhaus wanted to simultaneously free the individual power of self-expression and to develop an objective aesthetics based on scientific knowledge. It is necessary to grasp its idea of freedom as well as its ideal of order (Whitford, 1992). Gropius called an architect 'a co-ordinator' rather than an artist in the traditional sense. As self-expression did not mean personal content as an arbitrary caprice, but instead meant power to use creatively the result of scientific investigation and technological development which ordered primarily the establishments of standards capable of creative variation (Whitford, 1992).From the literature review, it is deduced that design is the direct result of specialization. Great lessons can be learnt by Jua Kali designers if they emulate developments of Bauhaus Design School which produced some of the world's best designers. To those designers, quality is a top down phenomena, first projected in the mind then produced. How the Jua Kali designers handle and organize their workshops, clientele, finances, labour issues and skills, proprietors and apprentices terms of employment determines the quality of their products (Gichiri \& Njuguna, 1984).Because the Jua Kali were found to duplicate a single design, a few designs presented in (Figures 6 \& 7) by students of the School of the Arts and Design of University of Nairobi were used to show the possibility of differentiation.

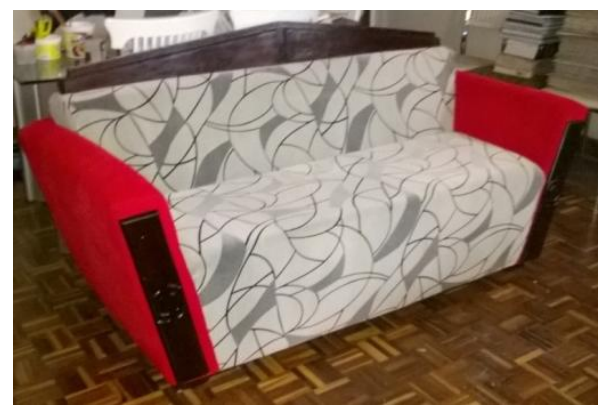

Figure 6: A chair designed for the reception area Source: Design students project 2015

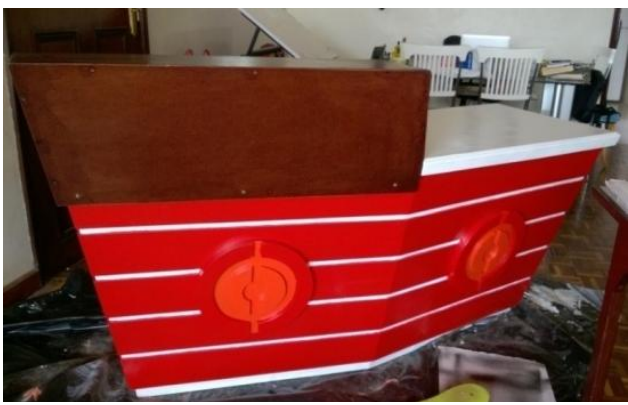

Figure 7: A desk designed for the reception area

Source: Design students project 2015

In the paper titled "Product design in less industrialized economies: constraints and opportunities in Kenya" by 
Krista M. Donaldson, it was observed that design process was not a serious consideration for any of the interviewed informal sector artisans despite incentives by several NGOs (Donaldson, 2006). The types of products produced by an artisan were based largely on his training and experience. For example, an artisan produced sheet metal storage trunks because he knew how to make it and because customers purchased them. Guimara es (1995) suggested that "informal design" capacity existed among the informal sector enterprises. He researched in Northeast Brazil, although he ceded that it consists of "incremental innovations" rather than coherent processes. This caveat is supported by Kabecha (1998) who asserted that a tangible, sustained, and guaranteed rate of return must exist for any innovation to occur in the Kenyan informal sector.

\section{RESEARCH METHODS}

The research questions for this study were about how Jua Kali artisans can synthesise design and production for clients' satisfaction and how they can integrate industrial art and design parameters to produce quality products? This study covered Gikomba area in Nairobi geographical area because economic activities are vibrant; have problems in planning, job opportunities and local authority operations. The case study was used to observe and discuss with artisans through questionnaires while a survey was carried out to find the nature of operational conditions of both customers and artisans. Primary data was collected through interviews, observations and questionnaires administered to 300 artisans and 100 consumers selected randomly. Issues covered in the questionnaires included: Authenticity and workshop environment, knowledge and skills of the designers in terms of education, training and work production, Workshop environment, materials, plan and nature of the work and marketing of finished products. Data was analysed using spss and thematic and pictorial analysis.

\section{RESULTS}

The Gikomba market where the timber and metal Jua Kali workshops are found is characterized by the following aspects: the workshops are made of temporary materials. They house the woodwork machinery, storage of timber, finished furniture items. The workshops are two storey timber structures. The structures are supplied with electricity and not all weather roads. The workshops carried out diverse of activities upholstery, hardware shops, (for material, furniture related shops) making of furniture, furniture display, timber, moulding, glass decoration, stores for furniture material e.g. cloth, timber, glue (adhesives), recycled timber and drums, etc.It is observed that the raw materials used for furniture construction was within the vicinity of where the workshop were located. The machinery workshops for timber moulding, cutting, planning, painting cabinet glass, upholstery were all in close proximity to the furniture workshop.

\section{Production process}

The construction of any furniture had different stages where each stage was assigned to apprentice. For example to make a sofa set the stages were:

i) Sourcing for raw materials.

ii) Cutting the timber into the required dimensions. The inner timber was not planned.

iii) Fixing the pieces together to make the sofa set frame.

iv) Fixing elastics on the seat and rest areas of the sofa set.

v) Placing upholstery (budding).

vi) Placing the covering material on the upholstery.

vii) Fixing the mould legs and finishing moulding on the selected parts of seats like the frontal parts.

viii) Finishing with stain or paint in cash.

The observed feature of the Jua Kali Industry was that it was highly integrated in its production processes of the furniture. This meant the outsourcing for related services in furniture workshop was easy and convenient. This made the artisans have low overheads, thus selling their products at cheaper price than in formal retail furniture shops.The last stage of the construction of furniture was its collection. Most artisans said the furniture was collected within one or two days after completion. Because of lack of ample storage, most artisans take orders from clients who wanted work which would be completed fast. The artisans requested $60 \%$ down payment of their services and this ensured him that the customer can afford the prefabricated item. They discourage work on credit since they have to buy materials.

\section{Understanding the customers}

Most of the customers who buy in the Jua Kali Industry were found to cluster in lower category of the class strata. The average income was less than 10,000/=. Their education level was up to standard eight. The housing for majority of customers was informal, mainly were living in slum areas. The implication of this is that they looked for furniture that was affordable and easy to maintain. In terms of furniture design, they selected from furniture album photographs the furniture they liked in terms of appeal and tagged cost. It was established 
the customers bought the furniture from workshops that were close to their residence to cut transport cost. In most cases they used push cart to transport the furniture to their quarters. Further, Jua Kali is well integrated with the livelihood of certain sectors of economy, thus, their survival regardless of the quality of the product as discussed later.

\section{Workshop condition}

Figure 8 shows a general representation of 300 workshops studied in the research. A $100 \%$ of them were temporary in nature, with goods displayed outside in the open and at the mercy of the weather elements. The products show poor design and risky operation conditions (Figures 8 \& 9).

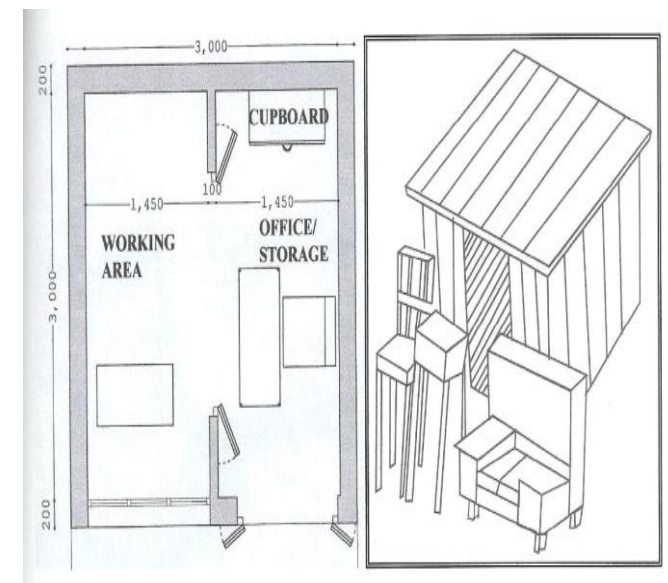

Figure 8: Cramped working space showing informality \& arbitrariness of design

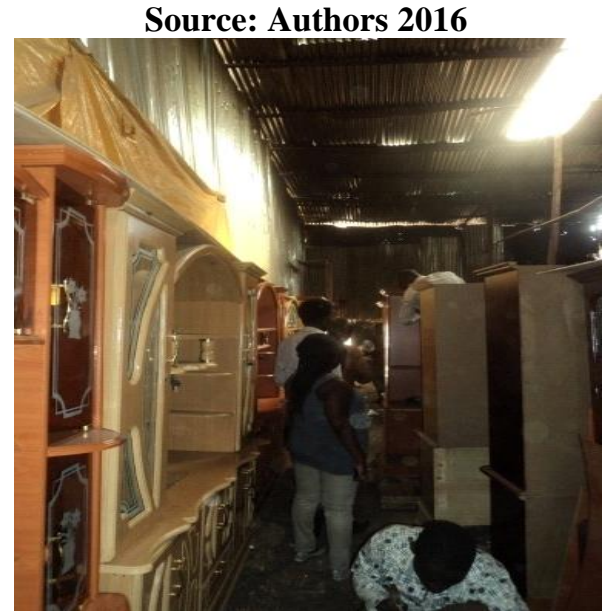

Figure 9: Cramped workspace Source: Field survey 2016

\section{Financial strain}

From the 10 business owners interviewed, six of them (60\%) accepted that one of the problems they face was lack of funds. Without funds, it was not possible to purchase quality raw materials, precision tools and equipment and at the same time hire reliable workshops. They found themselves not credit worthy because of the unpredictable nature of their operations. Access to finance would enable them hire reliable workshops, buy precision tools and get quality raw materials to produce quality articles. They sell the artisans at cheap price as their products were of low quality. Products were simple as complex articles required resources which they lack.

\section{Affordability of articles}

There was an advantage that articles were affordable to a majority (49\%) of their consumers (Pie Chart 1$)$. The price depended on the time taken to design and manufacture, cost of materials, rent and overheads as well as cost of energy and water. Other factors considered include cost of skilled labour to develop original concept, cost of workmanship and production machinery charges.

Pie Chart 1: Prices of articles 


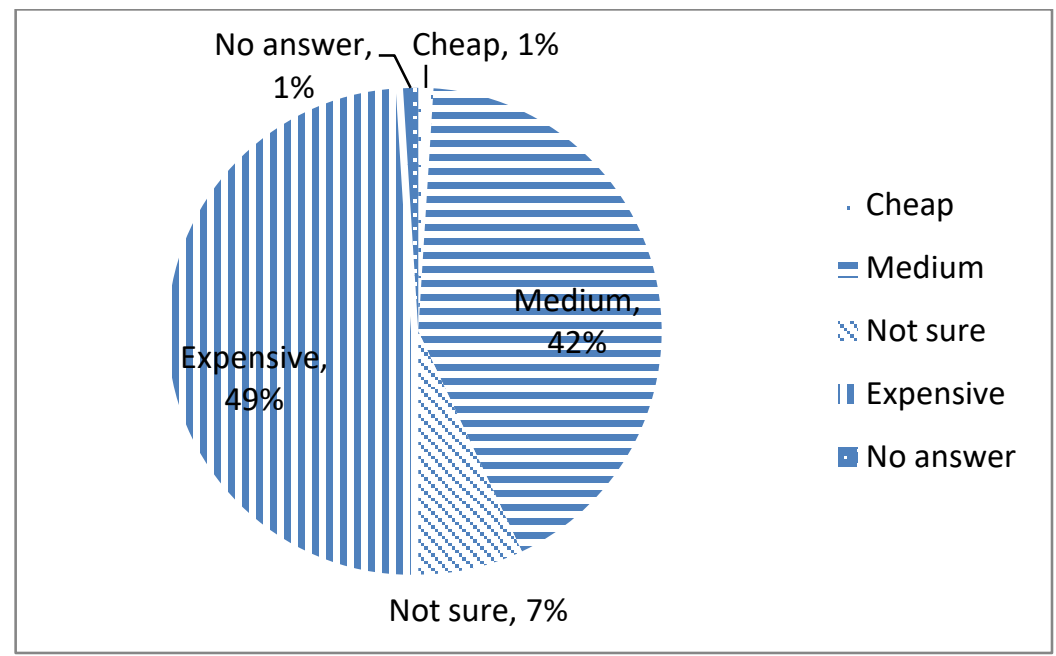

\section{Source: Field survey 2016}

\section{Labour}

Pie Chart 2 shows that out of the 300 artisans interviewed, the study revealed that $52 \%$ were on job training, 24\% were temporary workers, $19 \%$ were apprentices and only 5\% were on permanent terms of services. In a standard workshop in the informal sector, labour consisted of the proprietor, an assistant and or maybe two apprentices. The assistant and apprentices were of an age between 18 to 22 years, were mainly school drop outs and are related to the proprietor. In some cases they recruited trainees who worked for no pay or little pocket money. The situation improved where some trainees had been to polytechnics and institutes of technology spread across the country and were better placed than their unskilled counterparts. The proprietor was usually the manager, designer, producer, marketer and cashier and ran the workshop with little help from the assistant. This resulted to considerable shortcomings in design and production. Once the assistant had gathered necessary skills they move on to start their own enterprises and likewise recruit their own trainees and apprentices.

Pie Chart 2: Terms of employment

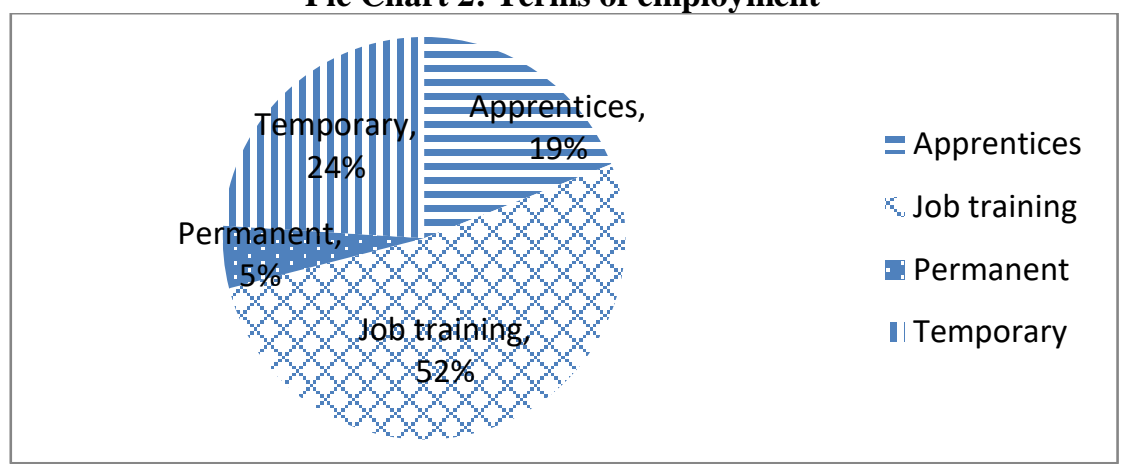

Source: Field survey 2016

\section{TOOLS OF TRADE}

$90 \%$ of the 300 artisans interviewed had a range of less than 13 tools shared among them while $10 \%$ of the well-equipped workshops had up to 40 tools shared among the artisans. This proved that many artisans lacked precision tools essential for quality production that would fetch higher price in the market. The kinds of tools the study found in use included but were not limited to the following types (Table 1).

Table 1: Tools of trade

\begin{tabular}{|l|l|}
\hline Tools used for timber work & Tools used for metal work \\
\hline Jack plane & Welding machine \\
\hline Try square & Welding rods \\
\hline Tape measure & Screw drivers \\
\hline
\end{tabular}




\begin{tabular}{|l|l|}
\hline Tenon saw & Hammers \\
\hline Hand saw & Pliers \\
\hline Screw drivers & Working table \\
\hline Chisels & Vice \\
\hline Claw hammer & \\
\hline Pliers pincher & \\
\hline Hand drill & \\
\hline
\end{tabular}

Source: Field survey 2016

\section{MATERIALS}

The study showed that a majority (71\%) of Jua Kali firms used recycled timber and scrap metal. These materials were normally rejects from the formal industry (Pie Chart 3). The $71 \%$ used the second hand or discarded items as it saves on cost. To achieve high quality products in terms of precision or aesthetics it was therefore not possible. The products could thus not compete with the formal sector.

Pie Chart 3: Source of materials

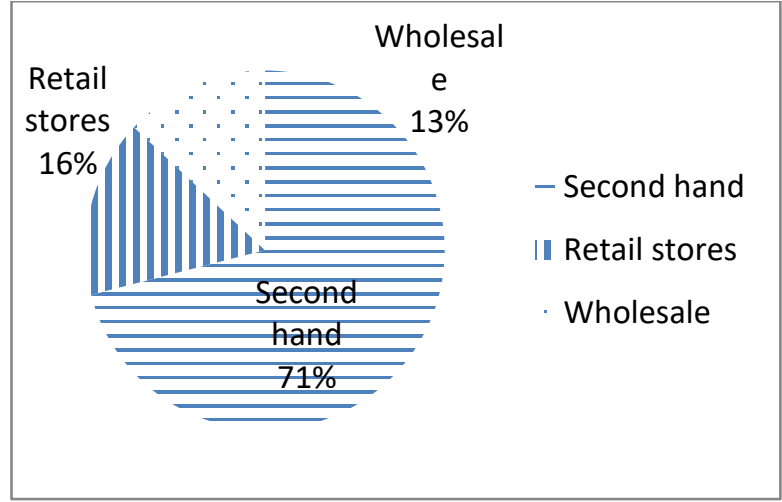

Source: Field survey 2016

\section{Consumer perception}

Of those surveyed on the issue of consumer perception to Jua Kali products (Pie Chart 4), 39\% said that the products were irregular in shape, $37 \%$ said the products were rough, $7 \%$ said they were ugly, $8 \%$ that they were fair, another $8 \%$ that they were beautiful while $1 \%$ abstained.

Pie Chart 4: Consumer perception of Jua Kali articles

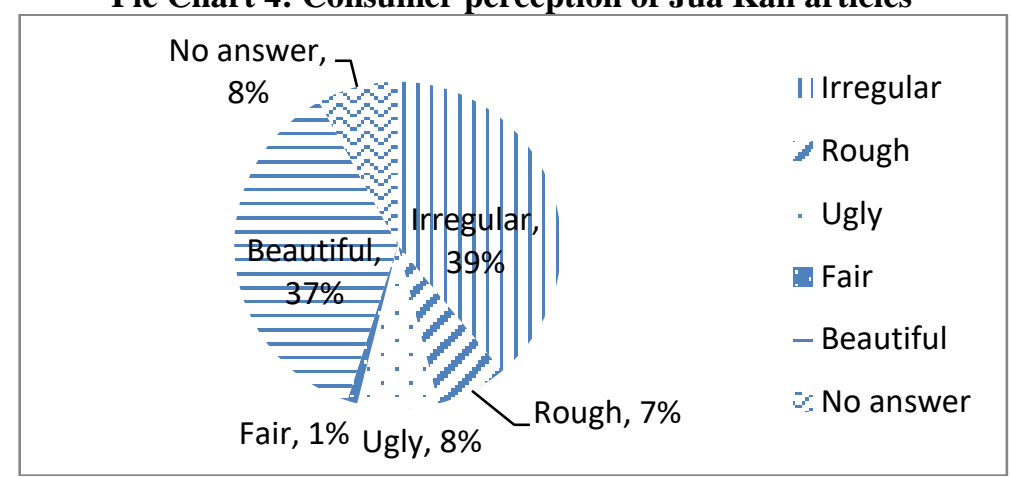

\section{Source: Field survey 2016}

From literature and in line with the above, the study established that good design should be products primary building block. This is because it makes the three things comprising of a "value pyramid" by insight possible (Figure 10). It proposes ways to introduce a product to the market, removes the negatives from the customers experience such as malfunctions from past designs and finally introduces the surprise. 


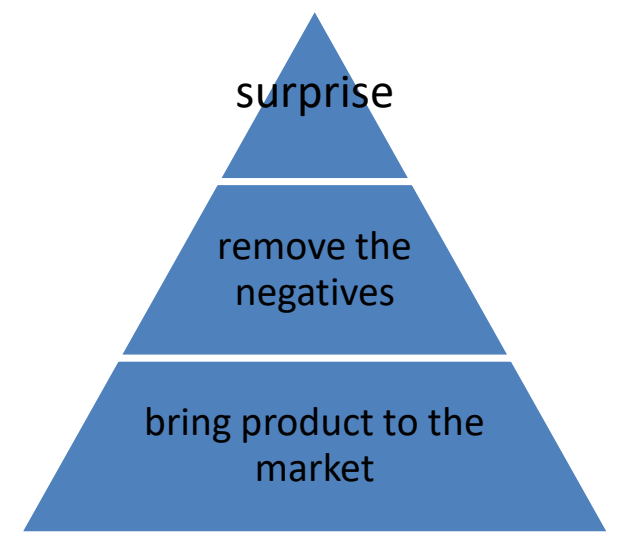

Figure 10: Value Pyramid

\section{Source: Insight World Services Limited 2014}

As shown on Pie Chart 5, as high as $67 \%$ of the artisans did not understand ergonomic considerations while designing and producing their articles. It was also observed that some chairs were stiff and uncomfortable to use. This question was based on the following background; In order for the user to feel comfortable, ergonomic consideration must be put to effect. The article must be flexible to accommodate head rest, vertebral column movement and bottom rest. The designer must also consider his working position. Comfort in position of usage by the consumer is mandatory while that of the manufacturer ensures maximum productivity.

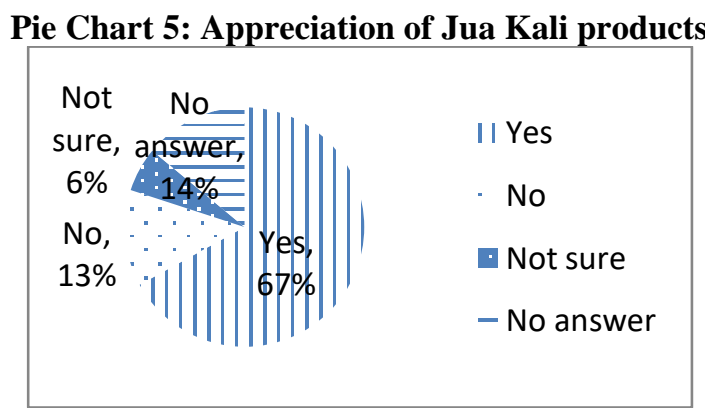

Source: Field survey 2016

\section{Design and Production Process}

The secondary data revealed that the design and construction process involves the consumers placing their orders to the designer using a brief. The brief contains a detailed requirement of each client. The varied taste and individual needs of consumers make it difficult to have standard designs for everyone. The majority of Jua Kali had no capacity to interpret the client brief and offer the unique solution of his requested product. This was attributed to lack of prior design education in formal institution and apprenticeship based receiving designing information from artisan with no formal education. Evidently, as revealed by the study, Jua Kali workshop managers lack precision tools to produce their products. It was established that this was attributable to lack of funding from lending agencies and banks. The temporary nature of the business makes them not keep sophisticated equipment because of security risks. In order to be effective in woodwork and metalwork, there is need for a range of high precision machines which they do not have and thus their wares are never steady in outlook and function (Figures $11 \& 12$ ). About half of the Kenyan artisans indicated that improvements to a product might be made following repair requests from customers, but any product modifications were strongly dependent on the perceived value to the customer and the time and cost involved for the artisan himself. 


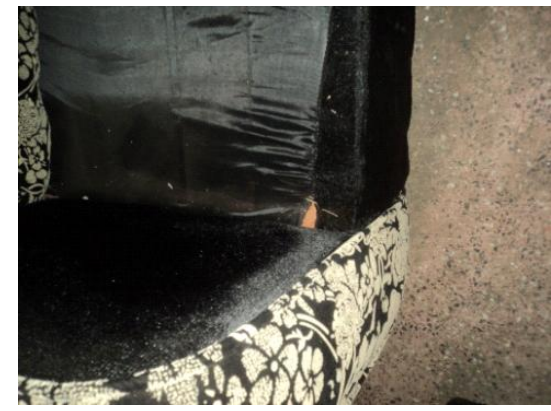

Figure 11: Torn fabric. No intention of repair Source: Field survey 2016

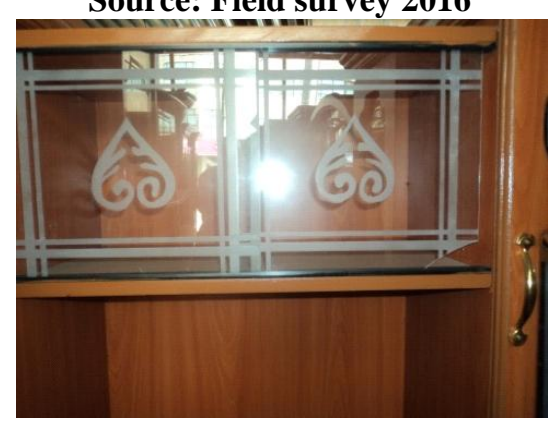

Figure 12: Broken glass. No intention of repair Source: Field survey 2016

The artisans share their designs thus there was no creativity, originality and minimal variations. The study established lack of artistic and design skills. Their databases of designs were copied from existing furniture catalogues. A customer's total experience surrounding a product was vital in determining the impression he/she has over a product depending on the nature of design. The majority of artisans observed that the design process for them involves inception stage with client where they got verbal briefing and then negotiation of price. The client was told to select one of the items he wanted to be made for him at the display. Rarely did the Artisan encourage variation. Any variation cost the item much more the standard price. The second stage was the search of materials and then construction of the item; which literally similar to those in display.A focused group discussion with the Jua Kali artisans and consumer revealed that the Jua Kali exists for sole purposes of ensuring that every Kenyan, regardless of the location residence or incomes of members of family, affords the household artifacts. The artisans stressed that Jua Kali should be seen as an innovative sector, developing household products that meets the needs of majority of Kenyan, even the poor. They pointed out their products are designed to continuously improve while reducing input costs. They noted that the Jua Kali artisans work with the customers, material manufacturers and government to ensure that every citizen of Kenya can afford any type of house hold good. This lays the foundation for the well-being of each family, which is corner stone for any nation.

\section{SUMMARY OF FINDINGS}

This study concludes that there is lack of funds in the Jua Kali which had led to the inability to purchase materials and appropriate labour. It also identifies that there is limited design and production skill with no specialisation of labour. Amidst all these, one advantage noted is that articles were available to many consumers because of economies of scale in production. Most of the consumers were low income earners, hence serving a specific class of society.The materials used in production were substandard; hence resultant products were not appealing. Based on site visits to manufacturers and interviews with owners and workers, no coherent design processes were observed in this study. Early process design activity; shown in the first two steps of Figure 13, where it occurred, was not standardized even within the same organization. Design decisions were not documented, although in several cases, a firm or enterprise owner would tate that everything he needed to know relating to the design of a product or products was "in his head". The studied informal sector manufacturers were found to focus on the fabrication of affordable products rather than the design of new products or on-going improvements to current products or processes. The item producers copied from each other leading to serious duplication and hence low prices. Such low prices results in diminishing incomes leading to frequent bankruptcies of most artisan firms. A generic design process is included to indicate all the steps that 
should have been followed (Figure 13). From the researchers' interrogation, there was no evidence that the process was followed in whichever direction.

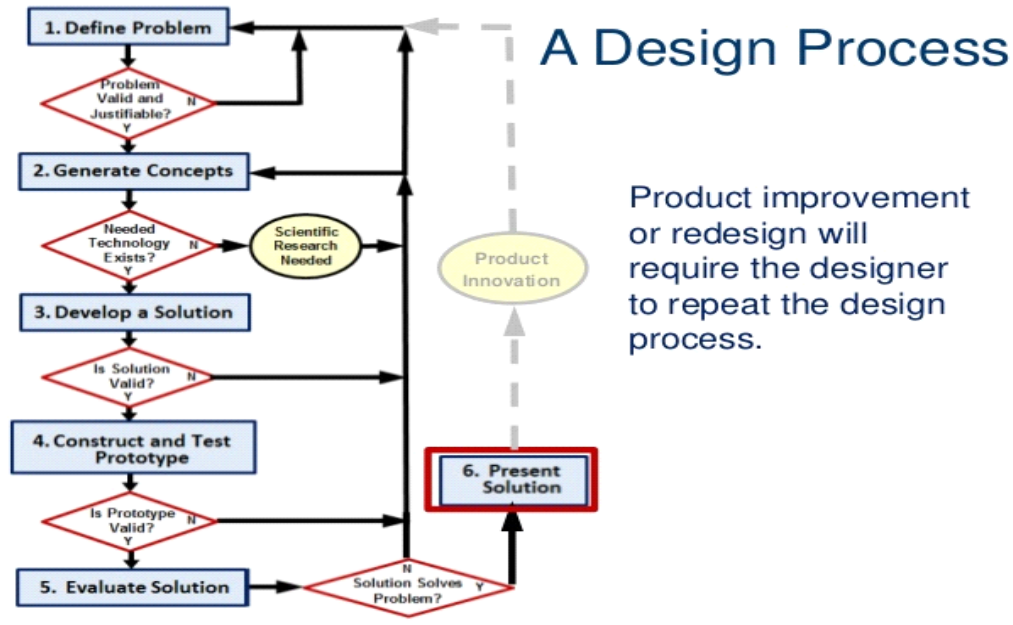

Figure 13: Product design process Source: Slideshare 2015

On necessary skills, the study found out that skills in joinery are mandatory in training to avoid furniture from rocking or disjointing after brief usage. An understanding of tools and their usage is needed for the job to meet required standards. The degree of specialization was wanting whereby one individual was carrying out too many varied jobs. Lack of access to quality materials, tools, and equipment as well as proper workshops led to continued manufacture goods with limited precision.

\section{RECOMMENDATIONS}

Of fundamental necessity to a quality product is the product design process, artisans in the informal sector should seek it and apply it. This paper advocates for specialisation in labour on design especially from conceptualisation and construction of the product and marketing on the same. It advises that conflicts in design due to duplication should be avoided by studying new approaches to design through seminars and exhibitions. Additionally, it emphasises the need for acquiring useful skills through training such as joinery so as to appropriately understand the tools and their usage. In line with the above, it is important to identify better quality materials bearing in mind the degree of elasticity and ability to make items more presentable and long lasting. This could be done by ensuring that the articles are creative and innovative. In conclusion, it recommends that, this sector takes into account experimentation with ergonomic considerations, consultation with trained industrial designers who would help design pleasant forms to keep up with the current design trends. These could earn them respect, build self-esteem and probably increase their fortunes tremendously. The study recognises that the sector serves a specific class of society and any change of how the sector work may interfere with affordability issue which is paramount to the low income earner. A very thoughtful solution needs to be sought.

\section{REFERENCES}

[1] Abagoye, A.A. (1986). Informal sector employment in Kenya. Addis Ababa: ILO, JASPA.

[2] Adrian, F. (1992). Objects of desire: design and society since 1750. New York, USA: Thames \& Hudson.

[3] Aleke, D. (1988). Enabling environment and credit infrastructure for SME in Kenya. Report for mini workshop held in Nairobi in May 1988.

[4] Armante, G.B. (1988). Idea and form in the history of construction. Wuppertal University, Germany.

[5] Donaldson, K.M. (2006). Product design in less industrialized economies: constraints and opportunities in Kenya. USA: Springer-Verlag London Limited.

[6] Gantz, C. (2014). Founders of American industrial design. USA: Mcfarland.

[7] Gichiri, N., \& Njuguna, N. (1984). Carpentry and metalwork in Eastlands of Nairobi. University of Nairobi, Nairobi.

[8] Guimara es LEC. (1995). Product design in the context of the social needs in less industrialised economies (PhD dissertation). The University of Aston in Birmingham, Birmingham, UK.

[9] Insight World Services Limited. (2014). The value pyramid: insight on how value is created. Retrieved November 17, 2015 from www.insight -ws.com. 
[10] Kabecha, W.W. (1998). Technological capacity of the micro-enterprises in Kenya's informal sector. Technovation. 19:117-126.

[11] Norman, D.A. (1988). The design of everyday things. USA: Basic Books.

[12] Onyango, H.W. (2002). A study of community industrial design in Kenya (PhD thesis). University of Nairobi, Nairobi.

[13] Rietveld, G. (c. 1923). Red and blue chair [Image]. In The Museum of Modern Art. New York: The Museum of Modern Art.

[14] Slideshare. (2015). Design process. Retrieved September 9, 2015 from image.slidesharecdn.com/

[15] Whitford, F. (Ed.). (1992). The Bauhaus: masters and students by themselves. London: Conran Octopus. 